cytochrome in the cell metabolism; and the concentration, purification and identification of various cell pigments. The bacterial eytochrome extracted from large quantities of acetone-dried cells appears to be quite distinct in properties from any cytochrome hitherto described. Studies on the breakdown of phtholic acid by a Gram-negative aerobic rod (NCIB 8334) isolated from an industrial percolating filter indicate that attack does not follow the degradative pathway via cis-cis-muconic acid described for several other aromatic compounds. Mutation studies have been started with this organism to obtain strains with a block in the metabolic pathway of phthalate oxidation.

\section{BIOLOGICAL AND MICROBIOLOGICAL METHODS OF ESTIMATING VITAMIN $B_{12}$}

A CONFERENCE on "Biological and Microbiological Methods of Estimating Vitamin $B_{12}$ ", organized by the Biological Methods Group of the Society for Analytical Chemistry, was held on May 13 in the lecture hall of the Royal Society for Tropical Medicine and Hygiene at Manson House, Portland Place, London. In his opening remarks, the chairman, Dr. L. J. Harris (Dunn Nutritional Laboratory, Cambridge), reviewed briefly the development of the present knowledge of vitamin $B_{12}$, from the discovery by Minot and Murphy in 1926 that pernicious anæmia could be controlled by the use of a liver preparation, to the isolation from liver of the curative principlevitamin $B_{12}$-by two separate groups of workers, one in Britain and the other in the United States. In the United States the isolation was greatly speeded up by the application of a microbiological control technique, based on the finding that the clinical activity of liver preparations was closely paralleled by their activity for a strain of Lactobacillus lactis, which had been shown by Shorb to require an unidentified growth-factor present in liver. Both the $L b$. lactis factor and the anti-pernicious anæmia principle were later identified with vitamin $B_{13}$.

During recent years, the Lb. lactis assay has been largely superseded by improved microbiological techniques, employing a variety of test microorganisms. In addition, the biological techniques with chicks and rats have been developed and improved. All these different techniques are attended by the inevitable problems of specificity of test, and in some cases of completeness of extraction. Dr. Harris then posed the question: How far do the different methods of assay measure the same thing ?

In the unavoidable absence of Mr. F. A. Robinson, his introductory paper was read by Mr. M. E. H. Fitzgerald (Allen and Hanbury, Ltd.). Mr. Fitzgerald pointed out the fundamental difficulties which can complicate the microbiological assay methods. The presence in natural materials of compounds closely related to vitamin $B_{12}$, inactive for higher animals and differently active for different test micro-organisms, can give misleading results. In some of the assays non-specific responses are caused by reducing substances, deoxyribosides or methionine. Then again, in some materials-milk and blood serum, for example-the vitamin is present in a bound form, unavailable to the test micro-organisms. Generally the vitamin can be liberated by heating or enzyme proteolysis in the presence of cyanide. But heating with cyanide does not in all instances release free cyanocobalamin. Mr. Fitzgerald pointed out that liver contains alkali-stable compounds that are active for the test micro-organisms, and among these may be an alkali-stable form of vitamin $B_{12}$.

A survey of published and unpublished values obtained for liver and liver extracts suggests the presence in them of a form of vitamin $\mathrm{B}_{12}$ active for Lb. leichmannii but not for Escherichia coli. Furthermore, it appears that neither organism responds to some clinically effective forms of vitamin $B_{12}$.

Dr. R. H. Girdwood (Department of Medicine, University of Edinburgh) considered the measurement of vitamin $B_{12}$ in the blood serum, and described in some detail his technique of assay with $L b$. leich mannii. By this method, normal values range between 130 and $750 \mu \mu \mathrm{gm}$. vitamin $\mathrm{B}_{12} / \mathrm{ml}$. Although to the clinician vitamin $B_{12}$ deficiency is asually synonymous with megaloblastic anæmia, a low serum vitamin $\mathrm{B}_{12}$-level may precede the development of anæmia. Dr. Girdwood suggested that probably the best way to measure serum vitamin $B_{12}$-levels is to use both the Lb. leichmannii and Euglena gracilis assays.

The next speaker, Dr. D. H. Shrimpton (Rowett Research Institute, Aberdeenshire), discussed the problems of measuring vitamin $B_{12}$ in animal feedingstuffs, using $L b$. leichmannii and Ochromonas malhamensis as test micro-organisms. In general, enzymic extraction procedures are unnecessary, and may in fact introduce non-specific growth stimulants. Autoclaving the test material with water at $p H 4.8$ in the presence of a trace of cyanide is usually sufficient to liberate the vitamin quantitatively.

The $L b$. leichmannii assay is subject to interference by deoxyribosides and by a variety of vitamin $B_{12}$. like compounds. In practice, in the tube assays, interference by deoxyribosides is only rarely encountered, except with materials very low in vitamin $B_{12}$ and rich in nuclear material. Similarly the vitamin $\mathrm{B}_{12}$-like compounds are of limited occurrence, being largely confined to natural materials that have been subjected to microbial fermentation.

Ochromonas malhamensis closely resembles the higher animals in the specificity of its requirement for vitamin $B_{12}$. But in practice the activity measured by micro-organisms is not necessarily a reliable prediction of the gross vitamin $B_{12}$-activity of feedingstuffs for higher animals. In fact, the results of a comparison of chick and microbiological assays of a variety of feeding-stuffs indicate that, in general, the less specific micro-organism, $L b$. leichmannii, approximates more closely to the findings by chick assay. This agreement is possibly fortuitous, but is nevertheless useful at the present stage of development of methods for assessing vitamin $\mathbf{B}_{12}$ activity.

Dr. Margaret E. Gregory (National Institute for Research in Dairying, University of Reading) described the measurement of vitamin $B_{12}$ in milk. Three test micro-organisms-Ochromonas malhamensis, Lb. leichmannii and Esch. coli-give closely similar results when used for assaying the vitamin in the milk of several animal species. For routine use, Lb. leichmannii is preferred as test organism, largely because no shaking machine is needed with it. A further advantage is that with turbid extracts the growth responses can be measured titrimetrically.

Vitamin $B_{12}$ occurs in milk, mainly as cobalamin, in protein-bound form. In cow's milk the vitamin can be liberated simply by diluting the milk with 
water and heating at $p \mathrm{H} 4.8$ in the presence of a trace of cyanide. In human and pig milk this simple procedure is inadequate, and it is necessary to liberate the vitamin by treatment with cyanideactivated papain.

In the next paper, Dr. Marie E. Coates (National Institute for Research in Dairying, University of Reading) discussed the biological techniques for the assay of vitamin $\mathbf{B}_{12}$. It is generally necessary to deplete the reserves of the test animals, either by restricting the vitamin $\mathrm{B}_{\mathbf{1 2}}$ intake of the dams or by the inclusion of stress factors in the diet. The chick is probably a more suitable test animal than the rat ; but both are likely to over-estimate the potency of crude materials containing unidentified growth factors unrelated to vitamin $B_{12}$. The presence of vitamin $\mathrm{B}_{12}$-like compounds does not greatly complicate the biological assays. Only the recently discovered vitamin $B_{12}$ III is active, and that only to the extent of one-twentieth of the activity of vitamin $B_{12}$. Although biological assays give a measure of the physiological availability for the test species, there is evidence that some of the naturally occurring bound forms of the vitamin present in one species may be poorly utilized by animals of other species.

The final paper of the conference was read by Dr. W. R. Pitney (Postgraduate Medical School, London), who considered the assay of vitamin $\mathbf{B}_{12}$ in blood serum, using Euglena gracilis as test organism. The assay is very highly sensitive, and only small volumes of serum are required. It is probable that, with serum, Euglena is specific for vitamin $\mathrm{B}_{12}$. Earlier reports of non-specific stimulants in occasional samples of serum may well have been due to contamination of glassware with vitamin $B_{12}$. Assays on 560 samples of serum have shown a coefficient of variation of 20 per cent, a degree of accuracy more than sufficient for clinical purposes.

Euglena assay shows that vitamin $\mathrm{B}_{12}$ in human serum is mostly bound to protein, and this finding is confirmed by dialysis and electrophoresis. Vitamin $\mathbf{B}_{12}$ in liver homogenates is assayed as 'free', but behaves on dialysis and electrophoresis as 'bound'. It is probable that vitamin $B_{12}$ occurs in two bound forms in biological materials-a firmly bound form in serum in which the vitamin is 'unavailable to Euglena without preliminary heating, and a looser combination in tissues.

\section{NON-DESTRUCTIVE TESTING GROUP OF THE INSTITUTE OF PHYSICS}

\section{SUMMER MEETING}

T

HE summer meeting of the Non-Destructive Testing Group of the Institute of Physics was held during June 22-25 in the Royal Technical College, Glasgow. On the evening of the first day, Sir Andrew McCance gave an address in which he traced the progress made, in his lifetime, by the introduction of physical methods into industry, and he emphasized the increase in speed and accuracy which has been achieved by the establishment of non-destructive techniques. He directed attention to the fact that future progress in the testing of materials is dependent upon the systematic investigation of physical phenomena, and he exemplified his argument by reference to the study of damping capacity. Later during the meeting Sir Andrew arranged for members to visit the Lanarkshire Steel Company and the Dalzell Research Laboratory, both of which are at Motherwell.

The first paper of the meeting, by Mr. T. S. Wylie (Department of Natural Philosophy, Royal Technical College, Glasgow), dealt with the course of training in radiography which forms part, albeit a small part, of the four-year course in applied physics at the College. Mr. Wylie showed how great is the care needed in planning the training so as to provide adequate instruction and experience when the time allotted to radiography can be no more than that covered by ten lectures and forty hours of work in the laboratory. He reported on the analysis, which he has carried out, of the requirements for a course in radiography, and explained, by reference to a number of charts and tables, how he has established a course in which the progress of the lectures is closely integrated with the progress of the experimental work and from which all unnecessary detail has been eliminated. During his lecture, and again in the discussion which followed, Mr. Wylie stated that he had found lack of knowledge of foundry practice on the part of students one of the biggest handicaps in the study of radiography; he stressed the need for students to spend time working in a foundry.

The importance of radiography to the shipbuilder has long been recognized, and Mr. Duffy (Clyde Shipbuilders' Association) explained how, at the time of the change from the use of riveted joints to welded joints, the Clyde shipbuilders combined together to operate an organized district scheme for the radio. graphic inspection of welded structures. He described the way in which this scheme operates and gave details of the equipment which is made available by it for inspection purposes. Owing to the difficulty of moving around ships with large X-ray units, the use of isotope sources for site work is preferred; and in this connexion Mr. Duffy remarked that, because of the portability of isotopes, their use shows considerable economy over that of X-ray units, even though longer exposure times are required.

Mr. Duffy dealt with the precautions necessary to protect personnel from radiation and high-tension equipment on site inspection. He then directed attention to the impossibility of carrying out a one hundred per cent inspection of the welds on a ship, and stated that the main object of radiographic examination in shipbuilding is that of testing the welder rather than the weld. Radiography is best used as a test for control of weld quality, and nobody should be allowed to make a single weld on a ship before his ability has been assessed by radiographing test plates welded by him. Mr. Duffy concluded his paper by describing the types of defects found in welds and by showing how radiographic examination enables wrong welding procedures to be detected.

Although the capital expenditure involved in the purchase of industrial boilers is large, this expenditure is small compared with the cost of the fuel consumed by the boilers. Boilermakers are, therefore, always trying to increase the thermal efficiency of their products, and this is done by designing boilers to operate at higher temperatures and pressures. The paper by Mr. W. E. Marskell (Babcock and Wilcox, Ltd.) was therefore concerned with the establishment of a system of non-destructive testing which would ensure the safe working of boilers. He 